\title{
Las Organizaciones Supramunicipales en España: las Comarcas
}

\author{
Joaquín Ferret i Jacas \\ Profesor Titular de Derecho Administrativo \\ Universidad de Barcelona
}

\begin{abstract}
SUMARIO: 1. INTRODUCCION. 2. LA COMARCA Y LA DISTRIBUCION DE COMPETENCIAS EN MATERIA DE REGIMEN LOCAL ENTRE EL ESTADO Y LAS COMUNIDADES AUTONOMAS: 2.1. La distribución competencial en materia de régimen local. 2.2. La distribución competencial en la articulación territorial de la Administración local. 2.3. La distribución competencial y el establecimiento y desarrollo de las comarcas. 3. NATURALEZA JURIDICA Y SIGNIFICACION DE LA COMARCA: 3.1. En general. 3.2. En los Estatutos de Autonomía. 3.3. En la legislación autonómica de desarrollo. 4. ORGANIZACION DE LA COMARCA. 5. COMPETENCIAS DE LA COMARCA. 6. CONSIDERACIONES FINALES.
\end{abstract}

\section{INTRODUCCION}

Un estudio sobre la comarca podría dedicar una parte importante de su espacio a señalar el conjunto de antecedentes históricos de carácter legal, político y social de este ente local intermedio, a constatar la existencia de estructuras locales de parecida configuración en el ordenamiento comparado (el Kreis alemán, los comprensori en Italia o los condados anglosajones, etc. 1) y, finalmente, a dar noticia de la abundante doctrina que, con más o menos textos legales vigentes relativos a

\footnotetext{
1 El tema de los entes locales intermedios en el derecho comparado ha merecido la atención de muchos autores. En general vid., por ejemplo, FONT i LLOVET, T., "Perspectivas de organización supramunicipal». En: Revista de Estudios de la Administración Local y Autonómica (REALA). Núm. 226 (Abril-Junio 1985); PALLARES MORENO, M., "La comarca e instituciones similares en el derecho comparado». En: La comarca y la administración territorial, IEAL, 1986 (Temas de Administración Local, núm. 18); PRATS i CATALÁ, J., «La comarca». En: MUÑOZ MACHADO, S., Tratado de Derecho Municipal. Madrid: Civitas, 1988; Y en particular, GIANNINI, M.S., «La experiencia italiana de los entes intermedios". En: La comarca com a ens territorial. Barcelona: Generalitat de Catalunya. Escola d'Administració Pública de Catalunya, 1984 (Col. "Materials", núm. 5); QUINTANA LÓPEZ, T., "Los entes locales complejos y otras formas de colaboración en el ordenamiento local italiano", en REALA. Núm. 241 (Enero-Marzo 1989); ESTEVE PARDO, J., "Organización supramunicipal y sistema de articulación entre administración autonómica y orden local (La experiencia de la RFA. Bases y perspectivas en España)». Madrid: Civitas-Diputació de Barcelona, 1991; CUCHILLO FOIX, M., "Els comats anglesos $i$ gal-lesos com a ens locals intermedis". Barcelona: Diputació de Barcelona, 1990.
} 
este ente, ha tratado profusamente dicha problemática. No es ésta nuestra intención, pero la referencia a antecedentes, derecho comparado y doctrina nos interesa para poner de manifiesto la gran significación jurídica y política que tiene la inserción de la comarca en el esquema de la Administración local.

El resurgimiento de lo que podríamos denominar «hecho comarcal» en el Estado español encuentra parte de su explicación en los cambios y aspiraciones que la transición política permitió cobijar. Como señalamos en otro lugar ${ }^{2}$, uno de los factores claves de dicho resurgimiento fue que en el contexto general de una nueva vertebración del Estado desde el optimismo democrático se pusiera un especial énfasis en la creación de nuevas estructuras y se pretendiese acercar al máximo las instancias de decisión al ciudadano, facilitándole además la prestación de más y mejores servicios.

El factor provincial no tiene un valor explicativo menor en relación con dicho resurgimiento. Efectivamente, el recelo ante el ente provincial -instrumento y exponente del centralismo liberal-, en ocasiones llevaba a la aspiración pura y simple de su supresión y cuando menos a fundadas dudas sobre la operatividad actual de sus dimensiones, así como sobre su legitimidad funcional al aparecer unas nuevas instancias, las autonómicas, que parecían superarla. Ello explica tanto la reivindicación del ente comarcal en un primer momento, como, posteriormente, el resurgimiento del sentimiento comarcalista y su progresiva plasmación legal. La difícil relación y convivencia de los entes del binomio provincia-comarca explicará asimismo el desarrollo legal y el grado de implantación del último de dichos entes.

La Constitución consagró el carácter fundamental de municipios y provincias, destacando al municipio como pieza básica de la ordenación local. Sin embargo, en la Constitución, el sistema de entes locales no se agóta en municipios y provincias. El artículo 141.3 permite «crear agrupaciones de municipios diferentes de la provincia» que, al igual que ella, podrán tener el doble carácter de entes locales y de circunscripciones territoriales para la desconcentración de los entes territoriales que los engloben y, asimismo, en el artículo 152.3 se dispuso que «Mediante la agrupación de municipios limítrofes, los Estatutos podrán establecer circunscripciones territoriales propias, que gozarán de plena personalidad jurídica».

2 FERRET i JACAS, J., "Ens locals supramunicipals». En: Les Comunitats autonomes $i$ els governs locals. Barcelona: Diputació de Barcelona, 1987. 
Como veremos, lo cierto es que, al amparo de estas previsiones constitucionales, en la práctica totalidad de los Estatutos de Autonomía se realizaron expresas previsiones relativas a la posibilidad o necesariedad de la existencia del ente comarcal en la organización territorial autonómica.

El presente estudio se interrogará especialmente por la naturaleza y caracterización que de las diversas fuentes legales resulta para la comarca, por diferentes aspectos relativos a la organización que, en su caso, se ha diseñado para estos entes y por el sistema competencial que tienen previsto. Dichos aspectos se analizan esencialmente en relación a la legislación emanada por el Parlamento de Cataluña, pero nos interesará igualmente referirnos a los ensayos y realizaciones que en esta materia se hayan producido en otras Comunidades Autónomas. Muy brevemente se pondrán de relieve otros aspectos que por su transcendencia o por la polémica que han desatado condicionan enormemente la existencia, funcionamiento y la propia pervivencia de este ente local intermedio que es la comarca.

Indudablemente la distribución competencial entre el Estado y las Comunidades Autónomas en materia de régimen local exige un análisis previo a las cuestiones reseñadas, por cuanto nos indicará hasta qué punto la disposición sobre las estructuras locales y, entre ellas, sobre la comarca es exclusiva de cada Comunidad Autónoma y hasta qué punto puede el Estado condicionar o compartir con ésta las decisiones relativas a su organización territorial.

\section{LA COMARCA Y LA DISTRIBUCION DE COMPETENCIAS EN MATERIA DE REGIMEN LOCAL ENTRE EL ESTADO Y LAS COMUNIDADES AUTONOMAS}

\subsection{La distribución competencial en materia de régimen local}

Aunque en la mayoría de los Estatutos de Autonomía la materia «régimen local"s se asume para la Comunidad Autónoma en régimen de exclusividad, dicha exclusividad tiene que ser inmediatamente relativizada y reconducida, como mínimo, al esquema bases-desarrollo, básicamente por dos circunstancias ${ }^{3}$.

\footnotetext{
3 Desarrollamos con anterioridad dicha afirmación en FERRET i JACAS, J., "Comentario núm. 27: Régimen Local». En: Comentarios sobre el Estatuto de Autonomía de Catalunya. Barcelona: Instituto de Estudios Autonómicos, 1991, vol. I.
} 
En primer lugar, porque dicha competencia se asume como exclusiva pero "sin perjuicio» de la competencia que en materia de bases del régimen jurídico de las Administraciones públicas atribuye en exclusiva al Estado el artículo 149.1.18 de la Constitución.

En segundo lugar, porque la jurisprudencia que ha sentado el Tribunal Constitucional impide desconocer la capacidad expansiva que encierra dicha cláusula constitucional.

En efecto, con anterioridad a los diversos pronunciamientos del Tribunal Constitucional, en Cataluña se formó una opinión que, basada en la cualificación como exclusiva de la materia por el Estatuto, interpretaba restrictivamente el alcance de la expresión «régimen jurídico de las Administraciones públicas» a la cual se conectaba las potestades estatales del mencionado artículo 149.1.18 de la Constitución. Así, la Comisión Jurídica Asesora de la Generalitat consideraba que "régimen jurídico de las Administraciones públicas» no podía significar otra cosa que la regulación del régimen de recursos y acciones que los administrados podían utilizar frente a las entidades públicas ${ }^{4}$.

Sin embargo, el Tribunal Constitucional no fue del mismo parecer y, contrariamente, en la interpretación que dio a la atribución competencial sobre bases que el apartado 18 del artículo 149.1 otorga al Estado ésta alcanza la totalidad del régimen local. Asimismo, el Alto Tribunal relacionó dicha competencia estatal para dictar bases del régimen jurídico de los entes locales con la garantía institucional de su autonomía, garantía que quedó configurada no solamente como un límite a la actuación de cualquier legislador —estatal o autonómico- sino también como un criterio de atribución de competencia al legislador estatal. La posterior evolución de la jurisprudencia constitucional reforzó la vinculación directa de los entes locales al Estado.

Se cerraba así el paso a la adopción de soluciones parecidas a la de los Estados Federales, e incluso a la postulación de la posibilidad de un "federalismo de ejecución», en virtud del cual dichas relaciones hubieran de articularse siempre a través de las Comunidades Autónomas. Dicha posibilidad y, en general, la concepción «intracomunitaria» de la autonomía de los entes locales que diversos preceptos estatutarios permitían defender fue rechazada en la Sentencia 84/1982, de 23 de di-

4 Vid. ARGULLOL MURGADAS, E., "L'organització territorial a Catalunya». En: Jornades sobre 1'Estatut d'Autonomia de Catalunya. Barcelona, 1980, publicado también en ARGULLOL MURGADAS, E., L'organització territorial de Catalunya, una perspectiva jurídica. Barcelona: Empúries, 1986 (Col. Biblioteca Universal, núm. 29). 
ciembre, en la que el Tribunal Constitucional proclamó la «bifrontalidad" de las autonomías locales, bifrontalidad de la que se pudo deducir la inclusión dentro de las competencias básicas del Estado de un buen número de competencias de ejecución.

A la complejidad resultante del reparto competencial se han de añadir los problemas de conceptuación del régimen local como materia. Dichos problemas arrancan del influjo de un sector de la doctrina alemana en la legislación básica estatal, doctrina para la cual el régimen local no existe como materia sino que se disuelve en los diferentes aspectos sectoriales que abarca y, consecuentemente, no es el régimen local lo que se atribuye como competencia a uno u otro ente, sino que la atribución competencial vendrá relacionada a los diversos sectores materiales que se regulan a nivel local. Cabe advertir, sin embargo, que el Tribunal Constitucional no ha aceptado las últimas consecuencias teóricas y prácticas a las que lleva dicho planteamiento y que sigue entendiendo que la expresión "régimen local» encierra un innegable contenido material.

\subsection{La distribución competencial en la articulación territorial de la Administración local}

La práctica compartición del título régimen local entre el Estado y la Comunidad autónoma de acuerdo con el modelo bases-desarrollo, así como la existencia de otras determinaciones constitucionales sobre la Administración local, como hemos visto, llevan a que una vez encuadrada una competencia en la materia régimen local debamos determinar aún si dicha competencia corresponde al Estado o a la Comunidad autónoma.

Uno de los aspectos en los que existen mayores posibilidades autonómicas es el de la articulación territorial de la Administración local y, más concretamente, en la fijación de los límites territoriales y en la caracterización jurídica de la naturaleza de los entes que la componen. Las previsiones contenidas en los preceptos constitucionales de aplicación, artículos 141.3 y 152.3, así como en los correspondientes preceptos estatutarios (por ejemplo, artículo 9.8, segundo inciso, del Estatuto de Autonomía de Cataluña) apoyan el criterio de la disponibilidad del legislador autonómico sobre las instancias territoriales. Dicha disponibilidad, sin embargo, no se extiende a la decisión relativa al mantenimiento o supresión de la provincia en sus diversas vertientes de circunscripción electoral, entidad local con personalidad jurídica propia y división territorial para el cumplimiento de las actividades del Estado.

Tampoco existe capacidad de decisión en relación a la simple alteración de los límites provinciales. La Constitución, en su artículo 141.1, reserva 
a la Ley orgánica - y por tanto, al legislador estatal - la alteración de dichos límites con fundamento en el carácter de circunscripción electoral de la provincia. La posibilidad que se apuntó en su día para el legislador autonómico en el sentido de poder alterar los límites provinciales en cuanto ente local fue rechazada por la legislación básica contenida en el Real Decreto Legislativo 781/1986, por el que se aprobaba el Texto Refundido de las disposiciones legales vigentes en materia de régimen local.

Sobre la indisponibilidad de la provincia para el legislador autonómico y la compatibilidad de su mantenimiento con la creación y funcionamiento de las comarcas volveremos más adelante.

\subsection{La distribución competencial y el establecimiento y desarrollo de las comarcas}

Las Comunidades autónomas no ostentan, como hemos visto, el monopolio de las decisiones relativas a la estructura local de su territorio. Esta afirmación es especialmente cierta en lo tocante a la provincia, pero quiebra prácticamente en relación con la comarca. Efectivamente, cada Comunidad Autónoma deberá atenerse primariamente a las determinaciones de su Estatuto de Autonomía para establecer y configurar con uno $\mathrm{u}$ otro carácter y de modo potestativo u obligatorio la instancia comarcal.

La Ley Reguladora de las Bases del Régimen Local (en adelante, LRBRL) respetó el carácter dispositivo que en relación a la creación de estos entes había consagrado la Constitución y plasmó una cierta voluntad autolimitadora de las competencias estatales que podían incidir en la configuración del régimen local (haciendas locales, régimen electoral, competencias sectoriales... ). El legislador básico parecía entender que la creación y . la configuración del nivel comarcal era una decisión esencialmente intracomunitaria y, consecuentemente, dejaba al legislador comunitario un amplio margen de actuación. Sin embargo, las Comunidades autónomas tampoco quedaron habilitadas para regular esta cuestión a su libre arbitrio, ya que mediante el artículo 42 de la Ley básica se establecieron una serie de limitaciones -discutibles y discutidas desde el prisma competencial $^{5}$ - a las cuales aquéllas debían ajustarse en todo caso.

\footnotetext{
5 Entre otros, por ENTRENA CUESTA, R., «Comentario n ${ }^{\circ} 10$; Organización Territorial». En: Comentarios sobre el Estatuto ...; ARGULLOL MURGADAS, E., "Las entidades metropolitanas». En: Organización territorial del Estado (administración local). Madrid: Instituto de Estudios Fiscales, 1985, vol. I; BAYONA ROCAMORA, A., "Descentralización y desconcentración en las leyes de organización territorial de Catalunan. En: Documentación Administrativa, núm. 214 (Abril-Junio 1988), pág. 138 y ss.
} 
El apartado segundo de dicho artículo estableció que en la decisión de implantar el nivel comarcal debía jugar decisivamente el principio de voluntariedad municipal, de modo que la comarca no se podía crear si se oponían las dos quintas partes de los municipios que habría de integrar, si éstos representaban, como mínimo, la mitad del censo electoral de dicha circunscripción.

Esta importante limitación a la voluntad del legislador autonómico, que podía resultar especialmente problemática en Cataluña si se atendía al mandato de su norma institucional básica, se salvó para dicha Comunidad mediante la disposición adicional cuarta de la LRBRL que, sin librarse de la polémica, permitió obviar el requisito de la voluntariedad municipal, en el caso de suponer oposición, a través de la mayoría absoluta de su Parlamento.

Dicho precepto ha sido objeto de crítica desde dos puntos de vista diferentes. En primer lugar, porque viene a fijar discrecionalmente una mayoría parlamentaria diferente de la mayoría simple en una Cámara legislativa autonómica que está obligada por mandato estatutario a aprobar la división comarcal. Y en segundo lugar, porque, en el momento de enjuiciar dicha disposición adicional, permitió al Tribunal Constitucional acoger la tesis de la posibilidad del legislador estatal de diferenciar territorialmente su normativa básica sin incurrir por ello, y por así decirlo, en agravio comparativo.

En la STC 214/1989, de 21 de diciembre, el Tribunal Constitucional justificó dicha posibilidad argumentando que las competencias estatales son diferentes según el nivel de competencias asumido por las Comunidades autónomas en sus Estatutos y que, siendo la comarca un ente necesario de acuerdo con el Estatuto catalán, requiere una regulación diferente en la legislación estatal. Ciertamente, otros Estatutos - "a los que para nada cita, sin embargo, la Disposición Adicional Cuarta" - 6 permitían sustentar una comarcalización general. Sin embargo, como señalamos en otro lugar ${ }^{7}$, la principal objeción sería otra: cualquiera que sea la regula-

\footnotetext{
${ }^{6}$ En expresión de FONT i LLOVET, que alude a los Estatutos de Asturias, Murcia, La Rioja y Comunidad Valenciana. Como el mismo autor indica, "En el sentido de no considerar discriminatoria esa solución en relación a Galicia, cuyo Estatuto no prevé la organización comarcal con carácter general: "Es ese dato fundamental el que marca esa separación entre una y otra Comunidad" ", como afirma la citada STC 214/1989, de 21 de diciembre, FJ 13 b). "La comarca y las estructuras del gobierno local». En: Tratado de Derecho Municipal, cit., pág. 279.

7 FERRET i JACAS, J. "Comentario a la Sentencia 214/1989, que resuelve los recursos planteados contra la Ley 7/1985, de bases del régimen local». En: Autonomias. Revista catalana de derecho público, núm. 12, pág. 316 y ss. Escola d'Administració Pública de Catalunya - Institut d'Estudis Autonòmics. Barcelona, 1990.
} 
ción estatutaria, se encuentra sometida a la Constitución y, por lo tanto, ninguna norma estatutaria puede impedir el dictado de la normas básicas al Estado ex artículo 149.1.18 de la Constitución. El Tribunal Constitucional, pues, admite que existen bases territorialmente diferenciadas. Y esta asimetría, a nuestro entender, no solamente no es negativa sino que concuerda plenamente con el diseño de las autonomías que quiere la Constitución.

Parecida o superior trascendencia tiene la limitación establecida en el apartado cuarto del artículo 42 LRBRL, según el cual en ningún caso la creación de las comarcas puede suponer la pérdida por los municipios de las competencias que la LRBRL señala como mínimas y obligatorias. Se frustra así —o se dificulta enormemente- la posible aspiración autonómica de implantar las comarcas con la voluntad de desterrar el eterno problema de la insuficiencia prestadora de servicios por parte de los municipios, insuficiencia patente e innegable especialmente a la vista del fragmentario mapa municipal de muchas de las Comunidades autónomas ${ }^{8}$.

La decisión básica según la cual los órganos de gobierno de la comarca debían ser representativos de los Ayuntamientos y no de los municipios que integrara parece condicionar decisivamente el sistema de elección de dichos órganos, cerrando el paso a un sistema de elección directa que quizás se hubiera adoptado por los legisladores autonómicos en aras de legitimar democráticamente el nuevo ente local huyendo del esquema electivo provincial 9 .

El desarrollo de todo el sistema de recursos financieros de las comarcas y su equiparación al mismo sistema de ingresos establecido

\footnotetext{
8 Así lo entiende también MIR i BAGO, J.: «Esta última limitación..resulta..poco congruente con una jurisprudencia constitucional, que ya conocemos, según la cual de la institución de nuevos niveles de administración territorial debe derivarse lógicamente la redistribución de competencias de los que existen con anterioridad... Además, tal como está formulada, esta limitación de atribuir a la comarca determinadas competencias municipales impide virtualmente llenarla de contenido competencial." La reforma del règim local a Catalunya. Barcelona: Generalitat de Catalunya. Escola d'Administració Pública de Catalunya, 1991, pág. 92 (Col. Estudis, núm. 9). Cabe señalar, sin embargo, que la LRBRL estableció y la legislación catalana ha desarrollado, como veremos, la posibilidad de los Municipios de solicitar de la Comunidad autónoma respectiva la dispensa de la obligación de prestar los servicios mínimos que les correspondan según el apartado primero del artículo $26 \mathrm{LRBRL}$, «cuando, por sus características peculiares, resulte de imposible o muy difícil cumplimiento el establecimiento y prestación de dichos servicios por el propio Ayuntamiento" (artículo 42.2 LRBRL).

9 Así lo entienden FONT i LLOVET, T.. «La comarca..., cit., pág. 287; PRATS i CATALÁ, J. «La comarca», cit., pág. 848; y MIR i BAGÓ, J. La reforma..., cit., pág. 91.
} 
para las mancomunidades por parte de la propia LRBRL y del posterior Texto Refundido de las disposiciones legales vigentes en materia de régimen local impide prácticamente a las comarcas que se instituyan gozar de unos fondos propios, y condicionan el presupuesto de las mismas a ingresos de carácter derivado, que ciertamente no reforzarán ni su autonomía de gestión ni la liquidez de su particular hacienda.

Podemos concluir, pues, afirmando que en lo relativo al establecimiento y regulación del ente comarcal el legislador autonómico ostenta una especial cuota de libertad legislativa, libertad que, sin embargo, ha sido objeto de importantes y hasta cierto punto inoportunas limitaciones por parte del legislador básico estatal.

\section{NATURALEZA JURIDICA Y SIGNIFICACION DE LA COMARCA}

\subsection{En general}

La naturaleza jurídica de las comarcas no resulta ni de la Constitución ni de la mayoría de los Estatutos de Autonomía: La LRBRL les otorga naturaleza de entes locales, pero no cita a la comarca entre los entes locales que gozan, además, del carácter de territoriales (municipio, provincia, islas). Dicha exclusión debe interpretarse en el sentido de una remisión al legislador autonómico para que, al tenor de las disposiciones del Estatuto que le vinculen o, en ausencia de las mismas, a su voluntad, caracterice o no las comarcas como entes locales territoriales.

El carácter necesario o potestativo de la existencia del nivel comarcal sigue el mismo camino. Su existencia no se impone ni a nivel constitucional ni a nivel básico. Serán los diferentes Estatutos de Autonomía o, en su caso, la legislación de las diferentes Comunidades los que impongan la obligatoriedad de la existencia de dicho nivel. A la misma conclusión cabe llegar, en fin, en relación a la posibilidad de establecer o bien una división comarcal en todo el territorio o bien una delimitación singular de una o más comarcas en dicho territorio.

Así, pues, la voluntad autonómica traducida en los respectivos Estatutos o en la legislación comunitaria que los desarrolle se constituye en el único indicador a tener en cuenta para deducir la concreta naturaleza jurídica con que cada Comunidad Autónoma ha configurado o, en su caso, configurará a la comarca. 
Paralelamente, la significación político-administrativa de este ente local variará en función de cuál sea la naturaleza jurídica con que se haya revestido a la(s) comarca(s).

Sin perjuicio de un ulterior análisis más detallado, podemos avanzar que en Cataluña la división de todo el territorio en comarcas resulta directamente del Estatuto catalán y que la legislación que lo ha desarrollado ha confirmado el carácter de ente local territorial de existencia general necesaria de la comarca catalana. Y en relación con la significación de la inserción de este ente local se ha destacado ${ }^{10}$ su múltiple funcionalidad en torno de los objetivos siguientes: la descentralización política de la Generalitat, la desconcentración de su Administración, la superación de la debilidad prestadora de muchos de los municipios y la equivalencia del nivel comarcal con una primaria o indirecta reforma municipal.

Sobre la regulación de la comarca en Cataluña volveremos más adelante en el momento de estudiar la organización y competencias comarcales. A continuación dedicaremos nuestra atención al análisis de la naturaleza jurídica y significación que en las restantes Comunidades autónomas se ha dado, en su caso, al ente comarcal

\subsection{En los Estatutos de Autonomía}

Como señala, entre otros autores ${ }^{11}$, Font i Llovet ${ }^{12}$, al margen de la cuestión de la denominación que evidentemente no es definitoria, está claro que la organización supramunicipal de ámbito comarcal está presente en todos los Estatutos de Autonomía, con la salvedad de las Comunidades autónomas insulares, que cuentan con la isla como especifíco ente local intermedio.

Efectivamente, al margen de estas dos Comunidades, los restantes Estatutos de Autonomía contienen una previsión en el sentido de poder o tener que contar con los entes locales intermedios de tipo comarcal. Explícitamente, la denominación de estos entes como "comarca» se encuentra en todos los Estatutos, con los casos del País Vasco, Navarra y Madrid como únicas excepciones.

10 BAYONA i ROCAMORA, A., "Descentralización y desconcentración...», cit., pág. 138-169.

11 Así, BARRIO ÁLVAREZ, M., “La comarca». En: Organización territorial del Estado (Administración local), cit., y PRATS i CATALÁ, J., op. cit.

12 "La comarca y las estructuras...”, cit., pág. 274. 
Sin embargo, lo cierto es que, como indica el mismo autor, la entidad comarcal que se introdujo en los Estatutos presenta una gran variedad de formulaciones, variedad que a primera vista dificulta considerar a esta institución como una única figura jurídica. El único elemento común que se puede destacar es el de la necesaria coexistencia de la comarca con la institución municipal de base. Más allá de este común denominador, los Estatutos abren un gran abanico de previsiones en relación a aspectos no precisamente insignificantes de la concepción de la comarca, como lo son el carácter necesario o no de su existencia, su naturaleza como ente territorial o institucional, el procedimiento para su creación o establecimiento, sus formas de articulación con la Comunidad autónoma, etc.

A nuestro entender, el tema de su necesariedad o no de acuerdo con el tenor de cada Estatuto es una de las más interesantes cuestiones al permitir prever un real establecimiento, más o menos lejano, de la comarca dentro de la organización territorial de esas Comunidades autónomas. Dicha necesariedad parece explicitarse con mayor o menor rotundidad en menos de la mitad del total de Estatutos y, concretamente, en los del Principado de Asturias, Cataluña, Murcia, Navarra, La Rioja y la Comunidad Valenciana, sin contar, claro está, con los de Baleares y Canarias, en los cuales también se configuran como necesarios los Consejos y $\mathrm{Ca}$ bildos insulares respectivamente ${ }^{13}$. En el resto de Estatutos la creación de comarcas o entes de similar naturaleza es tan sólo potestativa.

Donde también es posible detectar diferencias de importante alcance es en la cuestión de si la división del territorio comunitario en comarcas se puede o se debe establecer con carácter general para todo ese territorio (como sucede, además de en Cataluña, en la Comunidad Valenciana) o si la creación de comarcas es necesario realizarla individualmente mediante Ley específica, como ocurre en la mayoría de las Comunidades autónomas, en las que la comarca tan sólo es un ente local intermedio estatutariamente potestativo o no necesario.

El grado de interiorización de la comarca por parte de la respectiva Comunidad autónoma, es decir, de la cuota de capacidad de ésta para imponer y regular este nivel, o el grado de iniciativa dejado en manos de los municipios para determinar o instar voluntariamente su existencia dibuja también un amplio espectro de soluciones. Y la opción por una de ellas lleva aparejada unas repercusiones en lo tocante a la configuración de este ente sensiblemente diversas.

13 Asturias, art. 6.1 EAst; Cataluña, art. 5.1 EAC; Murcia, art. 3.1 EAMur; La Rioja, art. 5 EALRi; Valencia, art. 46 EACV; Baleares, art. 5.1 EABal; Canarias, arts. 2 y 7.2 EACan. 


\subsection{En la legislación autonómica de desarrollo}

Resumidamente, puede afirmarse que la mayoría de las Comunidades autónomas han seguido líneas de desarrollo legislativo diferentes de la comarcalización o desarrollo del ente comarcal. Muchas de ellas se han inclinado por regular la articulación y coordinación de las competencias entre las Diputaciones provinciales de su territorio y la respectiva Comunidad autónoma ${ }^{14}$. Otras han ejercido sus competencias legislativas o reglamentarias en el sentido de favorecer o fomentar la constitución de mancomunidades de municipios de fines específicos ${ }^{15}$. Otras, en fin, han permanecido inactivas y siguen manteniendo, con muy leves retoques, la estructura local que heredaron del pasado.

En cualquier caso, en la práctica totalidad de Comunidades autónomas en las cuales la comarca es potestativa no han creado o desarrollado este tipo de ente dentro de su territorio.

En más de un caso, tampoco en las Comunidades en las cuales la comarca se configuraba como un ente intermedio de existencia obligatoria se ha llegado a legislar en este sentido ${ }^{16}$.

Así, pues, podríamos concluir que, prácticamente, la comarcalización sólo se ha llevado a cabo en Cataluña. Sin embargo, esa conclusión pecaría de precipitación y, en este sentido, debemos señalar importante legislación en la materia de otras Comunidades. En el sentido de reiterar previsiones o regular la comarcalización, pero sin llegar a establecerla, en Asturias se reguló el procedimiento de creación de comarcas en el Principado por Ley 3/1986, de 15 de mayo. Asimismo, Murcia reguló por Ley $7 / 1983$, de 7 de octubre, la descentralización de su territorio y la colaboración entre la Comunidad autónoma y los entes locales situados en la misma y, posteriormente y con carácter

\footnotetext{
14 Andalucía, Ley 11/87, de 26 de diciembre; Aragón, Ley 8/1985, de 20 de diciembre; Castilla-La Mancha, Ley 2/1991, de 14 de marzo; Castilla y León, Ley 6/1986, de 6 de junio; Comunidad Valenciana, Ley 2/1983, de 4 de octubre; Galicia, Ley 8/1989, de 11 de junio.

15 Así, Aragón, Ley 6/1987, de 25 de abril y Decreto 56/1989, de 30 de mayo; Castilla-La Mancha, Ley 3/1991, de 14 de marzo; Castilla y León, Decreto 110/1984, de 27 de septiembre; Extremadura, Decreto 34/1989, de 9 de mayo; La Rioja, Decreto 22/1988, de 27 de mayo.

16 Así, en la Comunidad Valenciana y La Rioja. En Asturias y Murcia, como veremos, la legislación en materia de organización territorial se ha limitado a desarrollar y reiterar las previsiones estatutarias y básicas relativas a la creación de comarcas y a remitir a leyes posteriores la creación singular de las mismas.
} 
general, aprobó la Ley 6/1988, de 25 de agosto, de régimen local de la Región de Murcia.

Distinto a los anteriores es el caso de Castilla y León. En esta Comunidad, mediante Decreto 12/1984, de 24 de febrero, se creó la Comisión de Comarcalización y posteriormente, y hasta el momento, se creó y reguló por Ley 1/1991, de 14 de marzo, la Comarca del Bierzo, que agrupa treinta y ocho municipios de esa Comunidad ${ }^{17}$.

\section{ORGANIZACION DE LA COMARCA}

En Cataluña, nos hemos de atener a la Ley 6/1987, de 4 de abril, que estableció la organización comarcal y reguló, entre otros aspectos, los relativos a la organización, competencias, y financiación ${ }^{18}$.

Dicha Ley encomendó el gobierno y la administración de la comarca al llamado "Consejo Comarcal». La elección de sus miembros se basa en un sistema indirecto parecido al provincial y éstos se organizan mediante una estructura de clara raíz local, que consiste en la existencia de unos órganos necesarios establecidos por la misma Ley y de unos órganos de carácter complementario que puede crear el propio Consejo Comarcal mediante acuerdo de su pleno o aprobación del correspondiente Reglamento Orgánico Comarcal.

Son órganos necesarios del Consejo Comarcal, el Pleno, el Presidente, un Vicepresidente y la Comisión Especial de Cuentas. Las novedades

17 Ley publicada en el BOCL número 55, de 20 de marzo de 1991 y en el BOE número 96, de 22 de abril de 1991.

18 Dicha Ley no puede interpretarse aisladamente. La misma forma parte de un conjunto de cuatro Leyes aprobadas por el Parlamento de Cataluña el mes de abril de 1987 y desarrolladas con posterioridad que significaron una reforma general del régimen local y la organización territorial catalana y que, de acuerdo con las previsiones contenidas en la Constitución y en la legislación básica, regularon los distintos niveles de la Administración Local: Ley 5/1987, de 4 de abril, sobre el régimen provisional de las competencias de las diputaciones provinciales; Ley 6/1987, de 4 de abril, sobre la organización comarcal de Catalunya; Ley 7/1987, de 4 de abril, que establece y regula las actuaciones públicas especiales en la conurbación de Barcelona y en las comarcas comprendidas dentro de su zona de influencia directa; y Ley 8/1987, de 15 de abril, municipal y de régimen local de Catalunya. Con el objetivo de establecer la división comarcal, la Ley 6/1987 reiteró la previsión del trámite de consulta a los municipios, para lo cual señaló la división comarcal aprobada en Cataluña en 1936 como punto de referencia, y de la aprobación posterior del mapa comarcal por ley. Efectuada la consulta municipal el mismo año 1987, la división comarcal se aprobó por Ley 22/1987, de 16 de diciembre, modificada por Ley 5/1988, de 28 de Marzo. A raíz de dicha división comarcal, existen en Cataluña 41 comarcas. 
más significativas consisten, de una parte, en que también se configura como un órgano necesario la figura de un Gerente con funciones ejecutivas y, de otra, la no previsión con dicho carácter de la Comisión de Gobierno.

La Ley, siguiendo la lógica de la LRBRL de entender por órganos de las entidades locales a los de carácter electivo, no integra expresamente al gerente comarcal entre los órganos necesarios, pero tal carácter se puede deducir a pesar de la ambigüedad de la expresión de su artículo 13.2: «Formará parte también de la organización comarcal el gerente, con las funciones ejecutivas que determina la presente Ley».

Según el artículo 17.1 de la misma, corresponde al gerente dirigir la administración comarcal y ejecutar los acuerdos del pleno, así como las funciones directivas relacionadas con las obras y servicios comarcales, la autorización y el reconocimiento de gastos y obligaciones, el personal de la corporación y la contratación de obras y servicios cuya cuantía no exceda determinados límites. Dichas funciones, sin embargo, corresponden al gerente "de conformidad con las directrices del pleno y las instrucciones del presidente», por lo que la vinculación del gerente a dichos órganos y, especialmente, al último de ellos, resulta innegable. La configuración subordinada del gerente se refuerza también en lo tocante a las demás funciones que podrá ejercer, cuando expresamente le sean delegadas y no afecten a las atribuciones que la Ley confiere al presidente y al pleno del consejo comarcal.

Sin perjuicio de esta posición subordinada, puede afirmarse que el modelo de organización adoptado por la Ley responde al esquema de la gerencia, priorizando así los aspectos profesionales por encima de los representativos, pero asegurando la preponderancia de éstos. En este sentido, la novedad que representa la inclusión del gerente en la organización comarcal supone la posibilidad de dar a ésta un nuevo carácter, en función, sobre todo, de la cuota de poder que le reserven las directrices, instrucciones y delegaciones que reciba de los restantes órganos.

El hecho de que el Presidente no sea, como hemos visto, una figura exclusivamente representativa o simbólica puede comportar relaciones en clave de conflicto con el gerente, si la práctica comarcal opta por reforzar las atribuciones de este último.

En cualquier caso, la elección de uno y otro órgano corresponde al Pleno que, además de ésta, tiene atribuidas las decisiones más trascendentes de la vida comarcal y en favor del cual, además, otorga la Ley la competencia residual. A la vista del poder del Pleno cobra ma- 
yor importancia el mecanismo de elección de sus miembros, que debemos retomar.

Como se ha indicado, dicho mecanismo se basa en un sistema indirecto. El hecho de que la LRBRL dispusiera que los órganos de gobierno de las comarcas debían ser representativos de los Ayuntamientos (y no de los municipios) ha forzado la opinión de que la legislación básica impedía al legislador autonómico optar por un sistema directo de elección ${ }^{19}$. Lo cierto es que si bien el legislador habría podido aventurar una interpretación más arriesgada de tal precepto básico, entendiendo que no pretendía imponer una limitación de tan significado alcance e instaurando un sistema directo de elección, no lo hizo así. Todo ello ha comportado la configuración de unos entes comarcales desprovistos de la legitimación que confiere la elección directa por parte de los ciudadanos de su territorio, a diferencia, además, de lo que ocurre con entes de similar naturaleza. En palabras de Font i Llovet ${ }^{20}$, «la solución insinuada por el legislador estatal y concretada por el autonómico, en el sentido de prever la elección de segundo grado, contrasta con la tendencia que parece ser la más generalizada en otros ámbitos, y que es la de configurar a los entes intermedios como instituciones directamente vinculadas a la población subyacente y contemplar sistemas de elección directa para los mismos. En España lo encontramos en los niveles "propios" de distintas Comunidades Autónomas, como los Cabildos canarios, los Consejos Insulares de Baleares e incluso en los Territorios Históricos del País Vasco. Los órganos representativos del departamento francés, del "kreis" alemán y de la provincia italiana también son elegidos por sufragio universal y directo».

El sistema de elección previsto para los consejos comarcales catalanes es uno de los aspectos más conflictivos de su regulación y ha acarreado, además, el conflicto adicional en torno de la operacionalización concreta de dicho mecanismo. Este se basa en un sistema mixto que tiene en cuenta tanto los concejales como el número de votos obtenidos por cada formación política que haya superado un determinado porcentaje mínimo de votos en las elecciones municipales de la comarca. Con estas bases y con anterioridad a la aplicación de la regla de Hont se multiplica el porcentaje de concejales y el de votos correspondiente a cada formación política por las fracciones de $2 / 3$ y $1 / 3$, respectivamente. Basándose en el análisis de la actual correlación e implantación

19 Vid. nota núm. 9

20 Op. cit, pág. 287 
de fuerzas políticas en Cataluña, se han alzado voces 21 que señalan que al primar el mecanismo electoral el voto de los municipios pequeños y del medio rural, el Partido que controla el Parlamento y que se halla especialmente implantado en esos núcleos controla un mayor número de comarcas al que controlaría si se hubiera primado el voto de las poblaciones más habitadas, donde los partidos de la oposición parlamentaria se encuentran más implantados. La polémica no ha quedado en un nivel más o menos elevado de abstracción sino que se ha llegado a cuantificar con números y resultados 22 .

En relación con los órganos de carácter complementario la nota más destacable es la relativa a la creación del Consejo de Alcaldes por parte de diversos Reglamentos Orgánicos Comarcales. Dicho órgano permite dar entrada en el Consejo Comarcal a los Ayuntamientos que en aplicación del mecanismo electoral carecen de representación en el mismo y, a la vez, puede significar un primer paso de debilitación de la figura del gerente comarcal. A su vez, la creación de un órgano de este tipo desarrolla y concreta la ambigua previsión del artículo 19 de la Ley 6/1987, según el cual, «De acuerdo con lo que establezca el Reglamento Orgánico de la Comarca, el pleno del Consejo Comarcal puede convocar a los alcaldes de los municipios de la comarca para que informen de las decisiones de especial interés municipal, antes de someterlas a la aprobación del pleno". La literalidad del precepto descrito planteaba serias dudas acerca de si se trataba de la convocatoria de un órgano de carácter consultivo o de si sólo permitía la inserción de un simple trámite de informe dentro del proceso de aprobación de decisiones comarcales. La configuración del Consejo de Alcaldes como órgano complementario de la organización comarcal resuelve en este sentido las dudas planteadas.

En Asturias, la Ley 3/1986, de 15 de mayo, remite a leyes posteriores y específicas la creación de comarcas, una vez se haya ejercido la iniciativa de creación por parte de los sujetos que se encuentran legitimados para ello. Dichas leyes de creación de Comarcas deberán contener, en-

\footnotetext{
21 MARTÍN MATEO, R. "Entes locales complejos». Madrid: Trivium, 1987, págs. 202-203 y recordando, con PRATS i CATALÁ, J., op. cit, pág. 848, a SOLÉ TURÁ, J., «Episodis nacionals a Catalunya", en El País, de 11-04-1987, pág. 111.

22 Como lo recuerda MIR i BAGÓ, J., op. cit, nota 32 a la pág. 132: «la revista Catalunya Municipal, órgano de información de la Federación de Municipios de Cataluña, publicaba en el número 12 ( 25 de febrero de 1987) un estudio de Antoni Prunés, que simula la aplicación paralela del sistema electoral aprobado por la Ley de organización comarcal de Cataluña, y el mismo mecanismo aplicado únicamente en proporción al número de votos obtenido por cada lista electoral».
} 
tre otras previsiones, «la composición y funcionamiento de sus órganos de Gobierno". Sin embargo, la misma Ley 3/1986 establece que "Toda Comarca constará de un Consejo Comarcal integrado por representantes elegidos por cada Corporación de entre sus miembros, respetando su composición proporcional, tanto en cuanto al número de Concejales, como a su representatividad política. La Presidencia del Consejo Comarcal será colegiada y estará formada por un representante de cada Corporación Municipal, deferiéndose por turnos periódicos la Presidencia de las sesiones" (artículo 9.3).

En opinión de Prats i Catalá 23 , «Este sistema merecería una critica acerada y fácil si no fuese porque no vale la pena estudiar con detenimiento una legislación que, como ya dijimos, responde más al objetivo de dificultar o impedir que al de alentar o permitir la creación de comarcas. La difícil comarca asturiana tendría que representar no sólo a todos los Ayuntamientos de los municipios agrupados, sino a todos los grupos políticos de cada uno de ellos. Añádase a esto una Presidencia comarcal colegiada integrada por un representante de cada Ayuntamiento, y no será difícil deducir que se ha querido que, si a pesar de todo la comarca llega a nacer, resulte por completo ingobernable».

Donde la comarca ha tenido una materialización concreta más allá de su simple previsión ha sido en el caso de Castilla-León que, como dijimos, creó mediante la Ley 1/1991, de 14 de marzo, la Comarca del Bierzo. La organización de dicha Comarca sigue un esquema organizativo parecido al previsto para la comarca catalana del que, sin embargo, se distancia precisamente en sentido inverso a las novedades que aportó y que hemos señalado. En efecto, la Ley 1/1991 contempla de igual modo que la catalana la figura del gerente pero, a diferencia de ésta, no lo configura como un órgano necesario y ni tan sólo como un órgano de carácter complementario del Consejo Comarcal. Se determina que el Gerente tendrá la condición de personal eventual, cesando automáticamente cuando expire el mandato del Pleno que lo designó, y se le vincula estrechamente al Presidente del Consejo Comarcal. Así, según el artículo 19.1 de la Ley, "Si las necesidades funcionales de la Comarca lo aconsejan, el Pleno podrá nombrar un Gerente, que será el responsable de la gestión técnica y de la administración comarcal, bajo la superior autoridad del Presidente». Además de éste, también son órganos necesarios del Consejo Comarcal el Pleno y la Comisión de Gobierno. Como se ha indicado, la ley catalana no configuró a esta última como órgano necesario y sí lo hizo en cambio respecto de la Comisión Especial de Cuentas, cuya necesaria existencia

23 Op. cit, pág. 847. 
puede deducirse de la legislación básica, aunque no la cite expresamente la Ley de Castilla y León.

Ambas Leyes, sin embargo, coinciden en la posibilidad otorgada al Pleno para complementar, de acuerdo con los términos previstos en la legislación de régimen local, la organización por ellas establecidas, así como en la facultad de éste para convocar, de acuerdo con lo que se establezca en el Reglamento Orgánico, "a los Alcaldes de los municipios de la comarca, para que informen acerca de las decisiones comarcales de especial interés municipal antes de someterlas a la aprobación del Pleno" (Cataluña, art. 19 Ley 6/87 y Castilla y León, art. 23 Ley 1/91). Podemos reiterar aquí la duda que manifestábamos en el sentido de interpretar orgánica o procedimentalmente la última de estas previsiones.

\section{COMPETENCIAS DE LA COMARCA}

El régimen competencial establecido para las comarcas existentes o para las que en su caso se constituyan es uno de los elementos fundamentales a tener en cuenta para evaluar su posible funcionalidad y sentido. La cuestión es particularmente espinosa por cuanto este ente local intermedio debe convivir, lo quieran o no las Comunidades autónomas, con el nivel municipal, con el provincial en la mayoría de los casos, con la propia Administración central y periférica de la Comunidad, y con asociaciones o mancomunidades de municipios nacidas de la voluntad de parte de los municipios que lo integran. Con este panorama, es fácil adivinar que el sistema de competencias comarcales no consistirá en un haz demasiado extenso de funciones y potestades públicas. En efecto, dicho sistema se enfrenta con evidentes resistencias por debajo y por encima.

Por debajo porque, como ya pusimos de manifiesto, la LRBRL condicionó decisivamente cualquier régimen competencial que se adoptara al establecer en su artículo 42.4 que "La creación de las comarcas no podrá suponer la pérdida por los Municipios de la competencia para prestar los servicios enumerados en el artículo 26, ni privar a los mismos de toda intervención en cada una de las materias enumeradas en el apartado 2 del artículo 25", artículos que se refieren, respectivamente, a las llamadas competencias o servicios mínimos municipales y a las competencias sectoriales que la legislación estatal o autonómica deberá otorgar a los municipios en una diversidad de materias que la propia LRBRL enuncia.

En la hipótesis de que las comarcas se hallen realmente instituidas, su grado de aceptación por los municipios que integren determinará tam- 
bién con toda seguridad el nivel competencial de que puedan disponer. La resistencia de los municipios a este nivel local puede suponer una actuación de éstos al margen del nuevo nivel. Las principales manifestaciones de tal resistencia consistirían en el ejercicio por los mismos de todas las competencias que sean más o menos capaces de prestar, rechazando la posibilidad de delegación en la comarca, y en la constitución, para los servicios de carácter marcadamente supramunicipal de agrupaciones o de mancomunidades municipales para la prestación de dichos servicios. No es de extrañar, por lo tanto, que el legislador autonómico que pretenda favorecer a la comarca frente a otro tipo de estructuras locales regule restrictivamente la posibilidad que la LRBRL otorga a los municipios para crearlas.

Y por encima porque, como también indicábamos, en las Comunidades autónomas donde pervive la provincia como entidad local el legislador autonómico no ha podido disponer del nivel provincial. Las posibilidades de su simple y llana supresión o del vaciamiento absoluto de sus competencias han sido absolutamente cerradas al legislador autonómico por el legislador básico estatal y por la jurisprudencia constitucional. Las funciones de asistencia y cooperación que las Diputaciones provinciales venían prestando al municipio podrán concurrir con unas funciones comarcales análogas pero no desaparecer. La doctrina sentada por el Tribunal Constitucional, especialmente en su STC de 28 de julio de 1981, es clara al respecto. La legítima configuración del ámbito competencial de las Diputaciones provinciales por las Comunidades autónomas encuentra su límite en el necesario respeto a unas mínimas funciones que aquéllas tienen garantizadas, y sin las cuales quedarían como estructuras vacías de cualquier contenido.

Asimismo, el nacimiento de unas nuevas estructuras locales con un menor o mayor poder de actuación también puede suponer para la Administración autonómica un nuevo foco de conflicto o disputa competencial. El recelo de ésta ante tal situación es sin duda clave explicativa del escaso entusiasmo autonómico para desarrollar las correspondientes previsiones estatutarias o de la tendencia a interiorizar la comarca hasta el máximo permitido por la autonomía local, que en todo caso se deberá garantizar.

La Ley 6/1987, de 4 de abril, de organización comarcal de Cataluña, reguló un complejo régimen competencial en el que son patentes las dificultades manifestadas para configurar un espacio de actuación o capacidad comarcal que, como veremos, deberá articularse a partir de los espacios reconocidos a los entes locales o autonómicos existentes en el momento de su creación. 
De forma esquemática, puede decirse que las competencias comarcales se integran con las procedentes de tres fuentes diversas: a) las competencias propias; b) las competencias delegadas por la Generalidad y c) las competencias procedentes del municipio.

El rótulo de competencias propias, sin embargo, es hasta cierto punto arriesgado. En efecto, el artículo 25.1, siguiendo un esquema parecido al de la LRBRL, dispuso que "La comarca ejerce las competencias que le atribuyen la leyes del Parlamento, las cuales, en cualquier caso, deberán otorgar competencias sobre las materias siguientes: a) la ordenación del territorio y el urbanismo; b) la sanidad; c) los servicios sociales; d) la cultura; e) el deporte; f) la enseñanza ; y g) la salubridad pública y el medio". En todo caso, pues, serán las leyes sectoriales las que asignen efectivamente las competencias a las comarcas, las que concreten cuál es la actuación exacta de cada una de las instituciones que intervengan en la conformación del ámbito material por ellas regulado y las que establezcan las relaciones entre dichas instituciones. En todo caso, se trata de competencias futuribles. Las comarcas no nacen con ellas, sino con la simple aspiración de que les sean otorgadas con mayor o menor extensión en ocasión de ley sectorial sobre las materias reseñadas. La sujeción del legislador sectorial al mandato del artículo 25.1 ha sido irregular, olvidando tal mandato en algunas ocasiones y cumpliéndolo en otras 24 .

Sí merece, en cambio, el distintivo de competencia propia la que la Ley otorga a las comarcas en su artículo 36 en relación con la planificación territorial, respecto de la cual corresponderá a las comarcas ejercer el derecho de iniciativa para su elaboración, la recogida y coordinación de las propuestas municipales y la ejecución de sus determinaciones que también les corresponde en relación con los planes que elabore y apruebe la Administración de la Generalidad, en los que tienen reconocido el derecho de participación en su formulación.

En virtud del artículo 34 de la misma Ley, la comarca deberá ejercer funciones de estadística y establecer los medios para integrar la información de carácter municipal y comarcal, de acuerdo con la programación autonómica en la materia.

En relación con las competencias delegadas o asignadas por la Generalidad, prácticamente no existe en la Ley de referencia más que su previ-

24 Entre otras, han otorgado competencias a las comarcas las leyes sectoriales relativas al deporte (Ley 8/1988, de 7 de abril), abastecimiento de agua en el área de Barcelona (Ley 4/1990, de 9 de marzo), sanidad (Ley 15/1990, de 9 de julio), y museos (Ley 17/1990, de 2 de noviembre). 
sión y la remisión de su régimen jurídico a lo que establece la legislación de régimen local 25: "La comarca ejerce también las competencias que le delega o que le asigna la Administración de la Generalidad de acuerdo con lo que establece la legislación de régimen local» (artículo 25.3) 26 .

Mayor cuidado demostró el legislador autonómico en la regulación del régimen de las competencias procedentes del municipio. Este régimen consiste en la combinación de diversos mecanismos que han de hacer posible desempeñar a la comarca una triple función en relación con los municipios: completar los servicios municipales mediante el establecimiento de servicios complementarios o la realización de infraestructuras, la coordinación de la actuación de los diferentes ayuntamientos y su sustitución en los casos que sea necesaria. Para el ejercicio de esta última función se prevén diversas técnicas. La dispensa permite transferir a la comarca la prestación de un servicio de los cualificados como mínimos u obligatorios por la Ley básica y requiere la iniciativa municipal y el posterior acuerdo, mediante decreto, del Gobierno de la Generalidad. La conversión de competencias municipales en comarcales se refiere a competencias no cualificadas de obligatorias y corresponde acordarla a la comarca. Esta extraordinaria posibilidad tiene como presupuesto necesario que una ley la establezca expresamente o atribuya la competencia alternativamente al municipio o a la comarca y tiene señalados, además, importantes requisitos a cumplir: mayoría absoluta del pleno del consejo comarcal y ausencia cualificada de oposición municipal. El ejercicio de competencias municipales por parte de la comarca también puede venir establecido en virtud de delegación o convenio con los municipios, técnica que encuentra de nuevo su origen en la voluntad municipal y se inscribe en el libre acuerdo de voluntades entre las instituciones implicadas.

Una de las novedades de la Ley consistió en la regulación del llamado «programa de actuación comarcal». En este programa, que elabora y aprueba el pleno del consejo comarcal con la previa consulta a los municipios, deben contenerse las determinaciones reguladoras del reparto de competencias, atribuciones y servicios entre el municipio y la co-

25 Las técnicas de delegación y asignación de competencias a las comarcas por parte de la Generalidad encontraron inmediatamente su desarrollo en la Ley 8/87, de 15 de abril, municipal y de régimen local de Catalunya, artículos 122-127.

26 Estas técnicas se vienen utilizando con mayor decisión. Entre otras, se ha delegado en las comarcas competencias en las materias de actividades clasificadas (Decreto 346/1988), servicios sociales (Decreto 220/1989), transporte escolar (Decreto 219/1989), y cultura (Decreto 208/1989). 
marca, así como de sus relaciones de cooperación y coordinación. La Ley remite a este instrumento la compleción del régimen competencial que la misma establece. En función del tipo de municipios y de las necesidades específicas de la comarca, el programa de actuación deberá contener los criterios a los que deberán sujetarse los municipios para solicitar la dispensa de la prestación de los servicios mínimos, los criterios para la intervención comarcal para asegurar subsidiariamente una prestación adecuada de los mismos, las actividades y servicios municipales susceptibles de ejercicio comarcal mediante delegación o convenio y, entre otras determinaciones, el régimen del establecimiento y de la prestación de servicios supramunicipales complementarios de los municipales.

Finalmente, se reconoce a las comarcas funciones de cooperación y asistencia análogas a las que corresponden a las Diputaciones provinciales, y sin perjuicio de las mismas, así como el derecho a ejercer la iniciativa legislativa mediante la presentación de proposiciones de ley ante el Parlamento de Cataluña. La última de estas posibilidades trae causa del mismo Estatuto de Autonomía, que en su artículo 32.6 dispuso que la iniciativa legislativa también corresponde «en los términos que una ley de Cataluña establezca a los órganos políticos representativos de las demarcaciones supramunicipales de la organización territorial de Cataluña». Esta Ley de Cataluña, a la que el Estatuto remite, es la Ley 6/1987 que venimos analizando. Sus términos, sin embargo, no consagran con excesiva generosidad la iniciativa legislativa comarcal, que se sujeta a importantes limitaciones materiales y procedimentales.

Como puede deducirse, el régimen competencial de las comarcas se fundamenta principalmente en la voluntad de instancias diferentes a este ente. Depende en una alta proporción de la cantidad y cualidad de las competencias que el Parlamento decida otorgar a las comarcas mediante leyes sectoriales, del mayor o menor entusiasmo delegador y asignador de la Administración autonómica y del grado de confianza municipal en el ente de soporte y suplencia que puede ser la comarca.

La combinación de todos estos factores con la posibilidad o voluntad de cada comarca para la prestación de servicios y la realización de actividades puede comportar una particular diferencia competencial entre los diferentes consejos comarcales. Frente a la imposición de un régimen competencial uniforme, dicha variedad competencial permitirá a los distintos municipios catalanes adaptar a su voluntad y necesidad las nuevas instancias territoriales.

El régimen descrito ha seguido, a grandes trazos, las siguientes líneas de desarrollo. La legislación sectorial del Parlamento catalán no se ha 
caracterizado por una interpretación excesivamente generosa del precepto nuclear relativo a las llamadas competencias propias, sino que se ha limitado a otorgar algún tipo de competencias a las comarcas básicamente cuando una ley ha regulado directamente o con carácter general una de dichas materias 27 . En ocasiones se detectan referencias a las competencias de "los entes locales» en general o se produce la conocida remisión reenviadora a las competencias que la legislación de régimen local les reconoce. En otras, el legislador evita el nivel comarcal por él mismo instituido y prefiere las relaciones directas entre la Administración autonómica y los municipios o, en fin, atribuye la totalidad de las competencias a dicha Administración sin reservar ninguna de ellas a los entes en que se organiza territorialmente la Generalitat de Catalunya.

Distintos autores han denunciado dicha situación. Reconocen, sin embargo, cómo las competencias que pueden ser objeto de delegación por la Comunidad Autónoma a las comarcas han alcanzado un mayor volumen potenciando, así, "la vinculación de la comarca a la organización administrativa autonómica, de la que pasa a configurarse más netamente como elemento de su organización impropia o indirecta» 28 .

La Administración catalana también se ha servido de la técnica de la asignación o encomienda de competencias autonómicas a las comarcas, poniendo de manifiesto la capacidad de estos entes para desempeñar indirectamente el papel de órganos periféricos de la misma. La funcionalidad de dicha técnica se encuentra más en un principio de organización de la Administración que en la voluntad de atribuir funciones a las comarcas con el fin de que éstas las ejerzan en un régimen de autonomía decisional.

Como se ha visto, es en el campo municipal donde el sistema competencial comarcal acentúa su proyección. En determinados casos, distintos indicadores permiten observar un progresivo traslado de las competencias y servicios municipales de interés o repercusión superior a dicho ámbito en favor de las comarcas. Un carácter más general tiene la función de promoción, dinamización y coordinación voluntaria que éstas van asumiendo en materia económica y cultural. La inclusión en los catálogos comarcales de puestos de trabajo publicados de plazas reservadas a profesionales de la animación cultural y la asistencia social es un fiel reflejo de esta situación.

27 Vid. supra nota núm. 24

28 FONT i LLOVET, T., "La comarca y las estructuras... », cit, pág. 289 y ss. 
La todavía compleja estructura de Administraciones públicas del Estado español y, consiguientemente, la difícil búsqueda e inserción en la misma de espacios competenciales para las comarcas constituidas o que se constituyan, justifica a nuestro entender este largo y, sin embargo, incompleto análisis del régimen jurídico de las competencias comarcales en Cataluña.

$\mathrm{Si}$, en desarrollo de las generalizadas previsiones contenidas en la mayoría de los Estatutos, se llega a la implantación efectiva del ente comarcal en otras Comunidades autónomas, se adoptarán, sin duda, parecidos esquemas competenciales.

Este es el caso de la Comarca de El Bierzo, creada por la Ley 1/1991, de 14 de marzo, aprobada por las Cortes de Castilla y León. Aunque no idéntico, el régimen competencial previsto se estructura de forma muy parecida al catalán. Las leyes sectoriales de dicha Comunidad pueden atribuir competencias a la Comarca en un listado de materias más amplio que el previsto en la Ley catalana 6/1987 pero, a diferencia de ésta, dicha atribución es simplemente potestativa. No se recoge ni la figura del programa de actuación regulador de la relación competencial municipios-comarca, ni la figura de la conversión de competencias municipales en comarcales, ni la técnica de asignación de competencias por parte de la Comunidad autónoma.

Sí está prevista la transferencia o delegación por parte de ésta de la titularidad o ejercicio de sus competencias, la delegación de las competencias que tuvieren atribuidas los municipios con las limitaciones establecidas en la legislación básica y la posibilidad de prestarles la cooperación y asistencia que éstos le soliciten. Sin llegar, pues, a la complejidad del sistema comarcal de competencias establecido en Cataluña, el de la Comarca de El Bierzo sigue sus líneas básicas de inspiración.

Hasta el momento, las demás consideraciones que pudiéramos realizar en relación con las restantes Comunidades autónomas serían exclusivamente de "lege ferenda». Si éstas llegan a jugar la opción comarcalizadora, el diseño competencial que se prevea será la resultante del distinto papel que las restantes Administraciones ostenten en cada comunidad y de la mayor o menor cuota de poder que estén dispuestas a ceder al eventual ente comarcal.

\section{CONSIDERACIONES FINALES}

Como hemos comprobado, la comarca está más prevista que realizada. Sin llegarla a establecer, algunas Comunidades han desarrollado sus 
previsiones estatutarias en ese sentido. En el caso de emprender la comarcalización dichas Comunidades no se encontrarán con el simple vacío. En Cataluña, en Castilla y León, y con caracterizaciones similares en otras Comunidades Autónomas, se cuenta con la experiencia del nivel comarcal como ente local intermedio distinto al provincial. Están también los ejemplos que nos ofrece el Derecho comparado, a los que simplemente nos hemos referido.

Dichas consideraciones comportan, a nuestro entender, que con la comarca se produce una nueva quiebra del tradicional uniformismo del régimen local español. Con las limitaciones que hemos señalado, cada Comunidad ejercerá sus competencias en uno $u$ otro sentido acomodando sus estructuras locales a sus necesidades y a las del pueblo que las conforma. Dicho ejercicio competencial abre las puertas a la variedad organizativa dentro y fuera de cada Comunidad. La organización territorial de cada una de ellas sigue líneas diversas desde las mismas previsiones estatutarias. Dentro de cada Comunidad Autónoma, se podrán arbitrar soluciones adecuadas a los deseos de comunidades específicas, como ha sucedido en Cataluña con la Ley 16/1990, de 13 de julio, sobre el régimen especial del Valle de Arán, que cumpliendo con una previsión expresa del Estatuto catalán, ha modulado orgánica y competencialmente el régimen comarcal general para posibilitar la recuperación de la tradición histórica, política y cultural de dicho territorio.

Frente a ello, el mantenimiento - ya no general- de la provincia como ente local sigue suscitando largas polémicas en las Comunidades autónomas que rechazan la inserción de la misma en su propia organización territorial. En palabras de Muñoz Machado ${ }^{29}$, su indisponibilidad por el legislador autonómico, dotado constitucionalmente de amplios poderes en relación al régimen local, es poco consecuente, especialmente si consideramos que dicho legislador está habilitado para crear entes territoriales nuevos de base corporativa y situarlos en demarcaciones supracomarcales de amplitud poco menor que la provincial, como se quiere en Cataluña con las referencias que contiene su legislación de organización territorial a la división del territorio en regiones que agrupen a las comarcas según su realidad geográfica, social, económica e histórica.

En Cataluña, dicha situación ha llevado al legislador autonómico a prever, mediante las posibilidades que ofrece la Constitución, la integración de las cuatro provincias catalanas en una sola. La no actuación de

29 MUÑOZ MACHADO, S., "Derecho público de las Comunidades autónomas". Madrid: CIVITAS, 1987, vol. II, pág. 212. 
REALA 254 (ABRIL-JUNIO, 1992)

dichas posibilidades, de resultados harto inciertos, y la preferencia por otras soluciones de carácter provisional produce un constante conflicto institucional, especialmente en lo relativo a las obras y servicios provinciales, e impide el desarrollo de las demás estructuras territoriales.

El interés de la comunidad y la gestión próxima y eficaz de los servicios al ciudadano deben presidir cualquier reforma administrativa que se persiga. Con las dificultades señaladas, una configuración decidida de las comarcas puede aproximar la consecución de dichos objetivos. En caso contrario, su falta de funcionalidad y por tanto de legitimidad, impedirán su efectiva creación o su mantenimiento. 